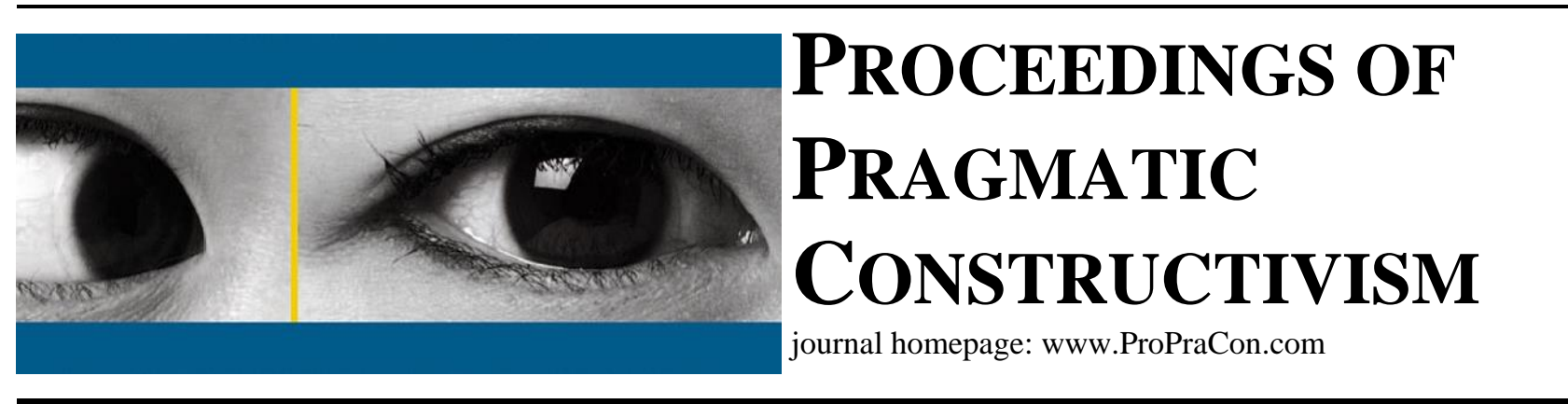

\title{
Do Business Models Co-exist within a Franchise - A case study on a Scandinavian Franchise Chain
}

\author{
Søren Guldbrand Asferg \\ Aarhus University; School of Business and Social Sciences; Department of Management \\ Bartholins Allé 10; 8000 Aarhus C; Denmark \\ Julie Dalbo Frost Christiansen \\ Aarhus University; School of Business and Social Sciences; Department of Management \\ Bartholins Allé 10; 8000 Aarhus C; Denmark \\ Charlotte Holdgård Jensen \\ Aarhus University; School of Business and Social Sciences; Department of Management \\ Bartholins Allé 10; 8000 Aarhus C; Denmark \\ Michael Henneberg Thomsen \\ Aarhus University; School of Business and Social Sciences; Department of Management \\ Bartholins Allé 10; 8000 Aarhus C; Denmark
}

\begin{abstract}
This case study seeks to add new knowledge about Business Models. More precise it investigates whether different stores within a franchise have different interpretations of their Business Model. The aim is to examine whether the different stores to some extent compete against each other. A Danish optician franchise was chosen, and two different store managers and one employee were interviewed. While there were no clear indications of internal competition in the franchise, there seemed to be deviations in the concept of Business Models in the different stores. For example the stores are targeting different customer segments, they have different opinions on how to measure the performance of the employees and the two managers have different approaches on how to manage the store. It was concluded that different business models could co-exist within a franchise, and that there was not much indication of internal competition between stores.
\end{abstract}

Keywords: Pragmatic constructivism; business models; co-existing business models; case study; franchise chain.

\section{Motivation}

Going through the academic literature on the concept of Business Models we get the impression that theorists assume that a company follows only one single business model. But is this actually the case or are there more than one business model present? This is an interesting aspect to consider because if there are more than one business model, then an internal alteration may not affect the whole company as expected. If multiple business models do exist within a company it will be interesting to investigate whether this has an effect on how they do business.

If there are different business models within a company, there could be some aspects that management needs to consider and take precautions. The existence of more than one business model can affect the image that a company wants to be associated with and the strategy they should follow. If an alteration is made based on the management's perception of the business models this might enhance some parts of the company, but might lead to impairment and 
resistance somewhere else. (Kotter 1995). If departments of a company do their business through different values, processes etc. an alteration of the business model might lead to inefficiency and damage the company brand from the customers' point of view.

Within the research field of Business Models, there has not been established consensus on how to define the term Business Models. There seem to be an overlap between the terms Strategy and Business Models when examining the definitions from these fields' leading authors (Osterwalder, Pigneur \& Tucci 2005, Seddon et al. 2004). Even though the interest in Business Models has increased over the last couple of decades (Bock et al. 2012), the concept has not yet established theoretical grounding in economics or in Business Strategies (Teece 2010).

Likewise, the research within the field of Management Accounting has its shortage in the term Business Models. Which is why the objective with this paper is to broaden the knowledge and understanding in the field of Business Models, with a main focus on establishing knowledge on the presence of co-existing business models. To do this, a case study has been conducted and through this we will examine the business model within a chain of franchise stores. With this case study we seek to examine if there are any differences in how the stores practice business. Perhaps, there are variations in how the different stores regard the overall business model of the firm. If this is the case then perhaps we will be able to argue for Co-existing Business Models through the findings and observations of the company represented in the case study.

Because of the lack in consensus in the definition of the concept of Business Models, we need to make a clear definition in this paper. A clear definition is needed in order to generate valid information through the case study and observations. If not, the findings will seem unsupported and consequently we will not be able to use the finding as a foundation to broaden and build new knowledge. Furthermore, we will not be able to increase the understanding upon the field of Business Models and the existence of Co-existing Business Models. In addition, creating a clear definition of the concept will make it possible to build future findings on this particular research and also make them comparable.

In order to do a meticulous case study together with the needed observations to help support the findings, a franchise chain with physical stores has been chosen as the subject of this paper. A chain of opticians has been selected as the foundation for the case study. Opticians still have a need for the physical stores because they are still a big part of the business concept. Customers still have a need for the services the physical stores can provide. The possibility to try on the different spectacle frames and the eye examination which cannot be offered or done over the Internet. The number of different opticians on the Danish market is profound and each chain has many stores located close together in the bigger cities. But how can a number of stores within the same chain survive in a market with almost perfect competition and the possibility for a very homogeneous market if they offer the same products and services?

This paper will aim towards generating new knowledge in the field of Business Models, more specifically in the area of Co-existing Business Models within the same franchise chain. We pose the research question: 'Do Business Models co-exist within a franchise?' We seek to answer the research question through a case study and observations in order to investigate how stores compete for the same customers within the franchise chain. Do they actually offer the same concept, or is it necessary for them to differentiate from the concept of the franchise chain?

\section{Conceptual background}

\subsection{Meta-theory-Practice Theory and Strategy-as-Practice}

In order to answer the research question, this paper draws on theories within the framework of Practice Theory and Strategy-as-Practice (SAP). Practice Theory was developed by multiple researchers such as Pierre Bourdieu, Anthony Giddens, Sherry Ortner etc. over a long period of time and basically builds on the idea that social life is an ongoing process which arises and changes through people's actions. The theory is well suited for organizational contexts as well and can primarily be dealt with in three main approaches. Firstly the empirical focus seeks to find how people act in an organization. It mainly answers the "what" questions in our research - what are the differences in how the stores do business within a franchise chain? Secondly the theoretical part tries to understand the relations between people's actions and the organizational structure and thereby the link between the micro- and macro level of an organization. This mainly answers the "how" questions by explaining our findings - how do the local practices influence the business models? The third approach is philosophical and focuses on social reality (Feldman, Orlikowski 2011, Vaara, Whittington 2012). In this paper the primary focus from these three perspectives will be on the empirical and theoretical approaches.

The theory of practice should prove useful to explain and analyze some of the conflicts our study might find in the case company. The social life in the organization is considered circular in the sense that all parts in an organization 
influence each other and contribute to the ongoing development process. The concept of power is included in the sense that all parties are not necessarily equally powerful, which is an important aspect when discussing organizational conflicts (Feldman, Orlikowski 2011).

SAP has its roots in the practice theoretical framework but focuses the research narrower towards areas such as Strategy and Practice Theory sociology. The focus is on how the production and reproduction of strategic action takes place and which participants take place in influencing the strategy making. According to the article by Jarzabkowski and Paul Spee (2009), research within SAP has three main parameters; the people who do the work of strategy (practitioners); the flow of activity in which strategy is accomplished (praxis); and the social symbolic and material tools through which strategy work is done (practices) (Jarzabkowski, Paul Spee 2009). Compared to much strategy research, SAP focuses less on "economic performance” and more on aspects such as political consequences, involvement of actors and other effects from different practices or praxis', which is more relevant for this particular study (Vaara, Whittington 2012, Whittle, Mueller 2010).

There are both internal and external practitioners, the first has direct influence on strategy making, while the second have an indirect influence, meaning not having an allocated place inside the organization. Originally, this boundary is drawn between the organization and the outside world, but in this analysis the boundary between internal and external practitioners is drawn between the individual stores and the headquarter (HQ). This separation is made because the HQ has some restrictions and regulations that the individual stores has to comply with, but besides that the stores are seen as separate and individual business units that act on their own to maximize profit. The HQ is therefore seen as an external actor in relation to the individual stores.

The second parameter Praxis deals with the activities inside the organization that over time forms the strategy, these activities are seen as interaction between the different practitioners (Jarzabkowski, Paul Spee 2009).

" 'Praxis is where operation and action meet, a dialectic synthesis of what is going on in a society and what people are doing' (ibid. 96), indicating that praxis may occur on more than one level.” (Jarzabkowski, Paul Spee 2009).

The third and last parameter practice is according to the article often grounded in the linguistic turn in Practice Theory, taking into consideration the discursive practice of practitioners (Jarzabkowski, Paul Spee 2009).

This methodology is useful when processing a majority of qualitative data in a single organization with multiple levels. Our own research deals with the concept of Business Models, which by many researches is considered fairly similar and often mistaken for, the concept of strategy. In the light of this it is considered fitting to use SAP to study the concept of Business Models. SAP researchers have regularly used qualitative case studies within single organizations. It is often based on interviews on multiple levels of the organization and observations, which is also the case in this particular study (Osterwalder, Pigneur \& Tucci 2005, Vaara, Whittington 2012, Seddon et al. 2004).

\subsection{Business Model definition}

Due to the lack of a clear definition of the concept of Business Models, this paper seeks to construct one to be used in this article. The concept of Business Models has been defined in several ways by a huge amount of authors (Osterwalder, Pigneur \& Tucci 2005). The increasing interpretations of this concept makes it necessary to give an explanation of this papers perception before any relevant meaning can be deducted from this study. The conclusion may very likely rest upon the use of the concept, meaning that this should be clarified beforehand. This paper seeks to build a definition of Business Models and use it throughout this article since a similar process have been applied by other authors within the subject (Osterwalder, Pigneur \& Tucci 2005, Casadesus-Masanell, Ricart 2010).

The definition of Business Models in this paper is constructed with inspiration from previous research trying to define the concept in order to take their findings into consideration. By doing this the intention is to generate a thorough and broad definition of the concept which future research can be compared to and developed upon.

The article by Johnson, Christensen \& Kagermann (2008) builds its definition of Business Models on four elements that basically include creating value for customers, creating value for the company (e.g. profits), key resources such as people and assets, and finally key processes (Johnson, Christensen \& Kagermann 2008). This approach is very focused on finding elements that are important in keeping the business alive and well. They define the concept by investigating its purpose. These concepts are part of the key to success and thereby they consider the business model of a company very important. 
The approaches applied by Osterwalder, Pigneur \& Tucci (2005) are different. They attempt to create their definition by splitting the words "business" and "model” and define its parts instead. They also create a definition by combining other authors’ perceptions of the concept to create their own (Osterwalder, Pigneur \& Tucci 2005).

Casadesus-Masanell and Ricart (2010) use a definition by Baden-Fuller et al. that goes by:

"Business Model refers to the logic of the firm, the way it operates and how it creates value for its stakeholders” (Casadesus-Masanell, Ricart 2010).

Their choice of definition is also the result of many other researchers but they build their argumentation on BadenFuller et al. and they argue that the concept of Business Models is divided into two parts. The first relates to management choices concerning how the organization should operate and the other to the consequences of these choices. The idea is that actions and choices made in the organization will eventually have an effect on other fractions of the firm and may influence these in different ways. This is a continuous process and can be seen as a "feedback loop" becoming more significant as such loops are carried out (Casadesus-Masanell, Ricart 2010). This indicates that a change in the business model may influence other parts of the company outside the Business Model definition.

Cavalcante, Kesting \& Ulhøi (2011) believes that an important property of a business model is that it should both be stable while remaining flexible for change. It should be possible to pursue new opportunities, without affecting the current processes of the firm. This will enable the company to exploit new technologies, and avoid path-dependence (Cavalcante, Kesting \& Ulhøi 2011). The same argument that business models should not be stable, but dynamic, is used by Johnson, Christensen \& Kagermann (2008) (Johnson, Christensen \& Kagermann 2008).

The concept of time in relation to Business Models is discussed in the article by Osterwalder, Pigneur \& Tucci (2005). Since a business model is "the way a company does business" this can only be a snapshot of the model (Osterwalder, Pigneur \& Tucci 2005). Companies change frequently but the concept is not fit to catch these constant changes, but it can act as a map of the company's past, current or future (planned) state.

Through the inspiration of these other articles a definition of Business Models has been constructed, which will be used throughout this study. Several matters of what this classification should include have been considered and a fairly broad one has been chosen to capture many relevant fields of interest. The final definition is as follows:
"A business model is the logic of how the company creates and captures value for the stakeholders. It is a snapshot of the firm, which enables dynamic changes. The choices they need to make concerning their key resources and processes, of how the firm creates and delivers value to the customers, and the financial, commercial and industrial consequences thereof".

The first and third sentence of this definition are strongly inspired by that by Casadesus-Masanell and Ricart (2010) and Johnson, Christensen \& Kagermann (2008) since they focus on how the company and subsidiaries are operated in order to create value. It is possible that these may vary between a company's subsidiaries and could create conflicted goals. It therefore suits the objective of this paper to find evidence of coexisting business models with these parts of the definition. The middle part focuses on time. To capture the above mentioned aspects the business model must be mapped only at one specific time to avoid the interference of constant change and to provide a simpler picture of the company. Although the business model of a company does not have to remain static, a new one can be made in the future to capture changes in the period between.

\section{Methodology}

\subsection{Case study method}

The case study for this research is conducted through the descriptions of Otley \& Berry (1994). The method of this paper is aligned with the ideas of the "illustrative case study" as it attempts to illustrate the studied organization in order to explain the observations conducted with applied theories. The objective is to increase knowledge within the subject of Business Models with a functionalistic view. This type of epistemology seeks to present different outcomes of actions or initiatives in the organization (Otley, Berry 1994, Ryan, Scapens \& Theobald 2002).

\subsection{Data collection}

The case study consists of multiple empirical sources of data drawn with separate gathering methods. The first data source is the interviews performed in collaboration with three employees within the case company. All interviews were 
conducted within 2-3 weeks to avoid major changes in the organization, which could influence the responses from each interview. The participants had different roles and worked at different levels in the organization. One manager administers several stores with numerous employees and were therefore expected to carry knowledge about the management of the stores individually and the relation to the HQ. The second is one of these employees and could contribute with the situation on the shop floor rather than the management level. The third administers a single store at another geographic location. These diversities gave us a broader insight and the opportunity to compare the responses. The interviews were conducted as semi-structured, with questions about the different parts of the Business Model concept, without revealing the topic. If they knew the subject, they might have based their responses on what they believe to be the right answer rather than what was actually the case.

The second data source is the webpage of the studied organization. Due to their wish to be anonymous the link to the webpage cannot be shown, but it will be referred to as "www.casecompany.dk". The website was used to gather information about prices on products, campaigns, product range etc.

The third data source consists of participant observation. Visits where made to multiple physical stores in two larger cities to observe store layouts, practices from a distance and informal conversations.

\subsection{Delimitation}

There are certain aspects that will not be discussed due to the extent of this paper and because it will lead the focus away from the main issue. Economic performance will not be discussed even though the internal performance evaluation of the employees will be analyzed. Economic performance goes beyond the scope of this paper and is not considered crucial to the stated definition of Business Model and therefore it will not be part of the analysis conducted. Additionally it has not been possible to collect these data from the case company. Because of the time frame and the resources available to conduct this paper, the amount of data collected is limited. As mentioned some data was not possible to collect and the opportunity to establish additional contact within the chain was limited. The content of this paper will only be established based on the definition of Business Model constructed earlier in this paper. Other definitions and interpretations of the concept will not be processed in this paper.

\subsection{Source criticism}

Working with this case study there is a need to acknowledge that there are some limitations regarding the data collection and analysis hereof. Therefore it is important to emphasize that the people interviewed in this case study have requested to read the finished paper. This fact might have affected the interviewees to limit the pronouncements made doing the interviews. At times the interviewees seemed to contemplate the answers more careful than others. The interviewees could perhaps have had concerns that some pronouncements could be misinterpreted if they were used in this paper.

Furthermore there is a need to acknowledge that because of the time frame and the resources available to conduct this paper, there is only collected data to a limited degree. Therefore it is important to question the data sources. It is questionable whether it is adequate to collect data through only three interviews and observations conducted. The findings of this paper could perhaps be better substantiated, if there were more data available, such as additional interviews. Unfortunately this was not possible, because of difficulties in obtaining additional contacts within the chain, and because of the extent of this paper.

\subsection{Case study}

The objective of this paper is to investigate whether different stores within a franchise have a different interpretation of what the business model of the franchise is. Case studies have experienced an increase in popularity within management accounting research during the last decades, because they enable researchers and practitioners to explain the underlying reasons for the topic in question (Dalby et al., 2014; Friis et al., 2015; Haubro et al., 2015; Larsen et al., 2014; Lueg et al., 2016; Lueg et al., 2015; Lueg et al., 2014; Lueg et al., 2013; Malmmose et al., 2014).Given the limited scope of this paper, the point is not to come up with a theory, which can be generalized, but rather to test if the phenomena of Coexisting Business Models exists.

Through the use of a deductive research approach (Ryan, Scapens \& Theobald 2002) the hope is that it will be able to support the initial hypothesis that the different stores within a franchise would show some deviations in how they do business. This hypothesis was then tested on a case company and supplemented by observations. The use of a case study supported the research question very well, in order to obtain profound knowledge about the phenomenon, 
and since it was not the intention to generalize the findings. A case study is also appropriate on research areas where theory is not well developed (Ryan, Scapens \& Theobald 2002), which is the case here.

To check the robustness of the findings of the case study, observations was made in the different stores to see if there was anything that could support or contradict them. The franchise homepage was also visited in order to compare the information here (from the HQ) with the information gathered through the interviews and the observations conducted.

\subsection{The case company}

When doing the fundamental work in order to write this article, the theme of this article was quickly focused on the subject of Business Models. Having read a great deal about the subject, the background knowledge and material lead to a quick draft of the research question. Working further with the theme it became clear that there is a lack of literature on Business Models and the coexistence hereof within the field of Management Accounting research (Seddon et al. 2004). The research question was then reformulated to focus on this specific area.

With a clear research question, there was a need to find a qualified candidate to compose the case study upon. A screening procedure of prospective candidates was discussed in order to identify a proper case company. A number of requirements for a company to qualify were considered to compose a set of operational criteria to judge whether a candidate was regarded qualified to serve as a case company (Yin 2014).

In order to explore whether business models co-exist, it seemed fitting to find a brand with a sizable number of stores. A chain of stores is not difficult to find, but to find one with many stores located on a small area greatly reduced the number of candidates. A second qualification that seemed appropriate when choosing a case company was the assortment. A company with a narrow assortment was prioritized to avoid a much too comprehensive analysis. This made the selection of qualified candidates decrease further.

A chain of opticians was suggested which seemed to satisfy the operational criteria. They offered many stores in a small area in the larger cities. Their assortment is deep and narrow as the determined operational criteria required. After having contacted two chains a connection was established within one of the chains, a store in City 1, which also arranged a connection in City 2. The contact in City 2 offered the opportunity to support potential findings in the data gathered from City 1.

The case company in this article is a franchise chain of opticians with stores located all over Denmark. In this article the concept franchise chain is used to describe a capital chain owned by a fund.

\section{Analysis and findings}

When analyzing the interviews it becomes apparent that there are two sets of rules that the stores follow - the formal and informal. These rules seek to be efficient guidance to provide the needed support for the employees in order to help the chain accomplish its objectives.

The formal rules are laid down in writing by the management (Das 2010). Through the interviews, it is made clear that there are some general rules that the stores have to follow. For instance this goes for decorations which the stores get delivered and just have to arrange 3-4 times a year, parts of the assortment are dictated from the headquarter and to some extent prices are set.

The informal rules arise out from the individual stores based on e.g. the employees' culture and social norms, and the service expected by the customers in the segment that the store target (Das 2010). Throughout the interviews, the interviewees do not state directly that there is competition internally in the chain. But when going through the interviews again there are some pronouncements that seem to indicate that there are some differences between the actions of the stores within the chain. These pronouncements appear to be further supported by observations made in the stores.

These indications of differentiation seem to be the informal rules that vary, which might be an indication of Coexisting Business Models within the chain. The analysis will investigate these pronouncements further and try to compare them with the observations. Hopefully this will help in answering the research question of the existence of Coexisting Business Models within a franchise chain. 


\subsection{Four sections - An overview of the analysis}

In order to do a meticulous analysis of the case company and the observations, this paper will approach the analysis in four sections. The aim is to generate as much knowledge and information as the collected data allows in the attempt to answer the research question as thorough as possible. A short overview of the four sections will be provided followed by the analysis. The first section seeks to explore whether the different stores understand and incorporate the concept of Business Model differently and investigate whether the stores differentiate from each other. The second section will examine if there are conflicts between the HQ and the stores, and if so the consequences thereof. The third examines if there is internal competition. The final fourth section investigates how they control and measure the employees to see if there are differences in how the stores are managed. A part conclusion will summarize the findings discovered through the four sections of the analysis.

\subsection{Section one - Variations in business models}

\subsubsection{Variations in the use of concept}

In order to analyze Co-existing Business Models it is required to clear whether the HQ and the stores in between understand this concept in the same way. In addition, do they incorporate the same kind of business model or does it vary in the individual parts of the organization? To make them comparable this study's analysis is based on the previous definition of Business Models.

Do the stores create value differently for their stakeholders, which include the stores, the franchise, the employees etc.? According to the interviewed managers there is an option to measure employee and store performance and use bonuses, but not all use it. Some question its effectiveness and reject it, while others use it to perhaps increase employee performance (Christiansen 2015a, Christiansen 2015c). This variation could have different effects on the business model. It can influence employee satisfaction to be monitored by management and it may also have an effect on the financial performance (Stanton 2000, Chalykoff, Kochan 1989).

The key processes, such as how they do their jobs, do not seem to vary much between the stores, although there are differences in their appearances. One of the stores visited had employees more formally dressed than some of the others. The showrooms in the stores are to some extent similar in appearance (Christiansen 2015d) because they want to represent a united front to show the customers that the chain has a strong brand and so the customer can recognize the brand. Because of the differences in the assortment, which will be discussed later in this section, there are differences in how the stores represent the assortment in their showrooms (Christiansen 2015d).

There is a distinction when they hire new employees. Since the store managers are in charge of this they look for people who satisfy their own needs. Depending on the criteria they desire, this also influences store performance and service level. According to both store managers interviewed they seek employees who are very service minded, but apparently not all stores prioritize customer service equally much (Christiansen 2015a, Christiansen 2015b, Christiansen 2015c).

Another important part of business models is how to create value for the customers and here the stores have great opportunity to differentiate. A lot of the products offered are decided by the HQ and sold nationwide, while others are picked out by the managers or employees of the store. On the official homepage the chain promotes the different price ranges and campaigns that are offered, which are the prices the stores follow (Anonymous 2015). In the interviews however, the interviewee revealed that in addition to these campaigns the stores have the option to make local campaigns.

\section{"It is allowed if some products are going out of stock (...) then we are allowed to make a local event, or give a special price...” (Christiansen 2015a).}

They can also choose to make price reduction on part of the assortment and lower the price of a product in order to make a sale and exercise a high service through this. This is an option even though they receive a price list from the HQ (Christiansen 2015a). This price list can be difficult to uphold with the different assortments in the stores.

They choose to make local campaigns to attract customers in the hope that they will make a purchase. Perhaps in order to acquire customers from the competing stores on the market and within the chain. In the interview, it is stated that if a customer wants to move their business from one franchise store to another, perhaps because they have moved their address, they will not say no to that customer. However, when asked whether they do anything intentionally to "steal" customers from other stores in the chain, the answer is a clear: "no" (Christiansen 2015a). This indicates that 
stores create value for their customers differently by offering different products, campaigns etc., which is a clear distinction in their use of business models.

Within the financial part there seem to be very little difference between the stores. They are all part of a franchise that owns the stores, which spare them a lot of financial challenges such as investments and the like. All the interviewees point this out but they also mention the expectations from HQ to reach sales, stay within budgets etc:

There are some clear expectations from HQ about what is expected" (Christiansen 2015b, Christiansen 2015c).

This could imply that despite the lack of financial issues, the difference in competition between the stores, challenges them in the quest to increase sales.

The above shows that the stores do practice different business models according to this study's definition of the concept. They create value for their stakeholders and customers differently. Perhaps due to the different issues the stores individually face, or perhaps to survive or compete against other stores both outside and inside the franchise. If these issues become a great concern for the franchisee they may pursue their own goals in order to resolve them (Baucus, Baucus \& Human 1996).

\subsubsection{Other diversities between the franchisees}

The focus is to explore additionally whether the stores differentiate or follow the same concept. As a starting point, it can be said that they automatically differentiate on some aspects. One aspect is the segment they reach through the individual store. This is connected with the fact that they are placed in different parts of a city. In the bigger cities, the demographics have a tendency to differ in the different parts of the city. Since the stores within the chain are not placed in the same geographical area, it is likely that they try to adapt to the needs of the local customers. In bigger cities, this will allow the franchise to satisfy the needs of a greater part of the market of this city and thereby reach out to more customers. If they all tried to reach the same types of customers they might not capture as big a part of the market as they otherwise would be able to.

Because of the difference in the demographics, the stores might need to change their assortment, because different types of customers demand different products. In the interview, it is mentioned that some stores sell more subscriptions on contact lenses than others (Christiansen 2015a). This might affect what kind of contact lenses the stores need to carry in order to sustain their customers and perhaps even to sustain a reputation that gives them a competitive advantage in the market and possibly within the chain.

A second point to consider is the selection of spectacle frames offered in the different stores. Through observations and interviews, it becomes apparent that there are differences on this matter as well. In the interview it is stated that it is the employees or the manager from each store that selects the part of the assortment that is not determined by the HQ. The spectacle frames are selected based on what the anticipated demand would be from the segments of their store. When selecting the spectacle frames they do not have to coordinate their choices with the other stores or the HQ. Additionally, some spectacle frames represented on the official home page (Anonymous 2015) are not necessary available in all stores. It is only the brands represented on the home page that to some extend can be expected available in all the stores (Christiansen 2015a, Christiansen 2015b, Christiansen 2015c, Christiansen 2015d).

Another aspect that is revealed through the interviews is that the service level differentiates between the stores as well. Some stores are more overbearing about which services are included in the purchase and which are not. Certain stores choose to go that extra mile that is necessary in order to get a satisfied customer who hopefully will come back another time, which others stores choose not to do.

In the second interview, the interviewee makes a pronouncement that supports this section. When asked if the stores carry the same selection of products (contact lens and spectacle frame), the answer indicates differentiation between the stores:

“...if you take the collection such as Ray-Ban. There are around 6000-7000 different spectacle frames. We perhaps carry 50. They are being selected based on the segment that is in the neighborhood where the store is. The segment here in this neighborhood" (Christiansen 2015b).

And when asked more directly, if they differentiate the products in the different stores, the answer is a clear yes:

"We differentiate on product mix and our staffing. These are the two areas where we differentiate from other stores within the franchise chain” (Christiansen 2015b). 
It is clear that the stores within the chain do things differently. This can be because the stores have different interpretations of the business model that the chain employs, or because the stores employ different business models. But it is clear that the stores differentiate to some extent. If the first is the case then this might be because they don't consider the business model at the level this analysis do or perhaps because they don't understand or agree with the business model (Baucus, Baucus \& Human 1996). The different interpretations of the business models might in fact lead to the creation of more than one business model, which support the latter statement.

\subsection{Section two - Conflicts within the franchise}

Through the formal rules the HQ defines how the different stores should operate, which products and models that have to be part of the assortment. Additionally the HQ defines the financial and non-financial performance targets that the stores and managers have to conform to. According to Baucus, Baucus \& Human (1996) this is common in relation to franchisors and franchisees way of allocating responsibility. They mention that the franchisor makes key decisions about how to operate the franchise (the formal rules), this can be in relation to product or services and standard prices for those products or services (Baucus, Baucus \& Human 1996).

Some of the guidelines and regulations that the stores must adapt are the price list, the stores are only allowed to give a certain amount of discount to secure that they offer the same prices in every store. Furthermore the HQ supplies the decoration and the stores have received a handbook on how the staff should appear and behave at work. This also include the dress code for the staff (Christiansen 2015a, Christiansen 2015b).

According to Baucus, Baucus \& Human (1996) consensus is an agreement and mutual supportiveness of franchisees and franchisors in relation to means of competition and desired end goals of the company as a whole. If there are no consensuses between the two, there are dissensions, which indicates that there is the possibility of conflict and contentious behavior (Baucus, Baucus \& Human 1996).

To investigate if there is goal congruence between the stores and the HQ, the easiest thing to do is to check whether the managers in the two stores enforce the dress code regulation set in the formal rules by the HQ. Because the managers and the employees are reluctant to provide knowledge about potential disagreements that could be present between HQ and the stores, it can be difficult to gather enough information on the subject through the interviews.

In the store in City 2 it was found that the manager enforced the dress code regulation, the employees wear neutral clothes, where either the top or the bottom were black or white, and they carried the required nametags. The layout of the store came across as being neutral, there were no personal belonging but a feeling of professionalism in the way the employees behaved. Through the observations conducted in the store the impression was that the store manager attempts to live up to the formal rules, which indicates that there is conformity between what the HQ and the local store want (Christiansen 2015d).

In relation to the store in City 1 and their enforcement of the dress code regulation, it was observed that the employees didn't comply with the dress code and that they didn't carry a nametag. When asked in a casual conversation, they said that they found the dress code to be unnecessary. The staff also said that they preferred this informal way of interaction with the customers. The employee mentioned that it was boring wearing black and white clothes and that there was no space for personality in the dress code (Christiansen 2015d). This is a clear example of dissension mentioned by Baucus, Baucus \& Human (1996). According to the authors, this can create a threat to the franchisor's trademark if there are no conformity between the different stores and how they appear to the customers.

\section{"Franchisees foster dissension by ignoring franchisors' goals in pursuit of their own entrepreneurial interests, possibly misrepresenting costs and revenues, or by withholding royalties” (Baucus, Baucus \& Human 1996).}

According to Brickley, Dark \& Weisbach (1991) it can be necessary for the franchisors to police franchisees to comply with the determined regulation for operations. On a follow up conversation with the employee from the store in City 1 , it was mentioned that the district manager had made a reprimand about the store not complying with the dress code and they were instigated to change this. The employee from the store in City 1 explained that they now were following the guidelines for the dress code and that they carried nametags, but that they weren’t content with it (Brickley, Dark \& Weisbach 1991, Christiansen 2015d).

In the article by Baucus, Baucus \& Human (1996) they conclude that there are significant differences on how the franchisees comply with the regulations set by the HQ and that this may lead to a conflict (Baucus, Baucus \& Human 1996). This can be related to how the two stores react to regulation from HQ in our case, the store in City 2 did not 
seem to have any disagreement about enforcing the dress code, where the store in City 1 was more reluctant and had to be reprimanded.

\subsection{Section three - Internal competition}

All the stores are owned by the franchisor and the store managers have not invested any money in the stores themselves. The store managers receive certain goals set by the franchisor that they have to fulfill. So while the managers have not invested in the store itself, the franchisor has clear expectations to the performance of the different stores. One of the store managers interviewed, previously owned his stores himself but sold them to the franchise some years back. The franchisor sets clear goals for the different stores in the franchise, so the store managers know what is expected of them (Christiansen 2015b). Since the store managers don't own the stores themselves, these goals are set to give them incentives to work hard to increase profit for chain as a whole. This way the franchisor makes sure there is goalcongruence between HQ and the store managers.

There are some guidelines that the managers have to live up to (formal rules), but apart from that the different stores have some opportunities to shape the store how they want to (informal rules). They have the freedom to choose part of their assortment themselves but the prices are set topdown. They are however allowed to have their own local campaigns where they lower prices on some of their products (Christiansen 2015b). While they are not allowed to set the prices of the individual glasses, they are allowed to have store sales, so they do have the possibility to, temporarily, set prices lower than the other stores in the chain. This could be used by the managers to game the sales expectations set by the franchisor. If a store is performing so badly that the manager is in risk of dismissal, he can start having a lot of sales in order to boost sales in the short term. If the store is having a sale they might steal some of the customers from other stores within the chain, who would otherwise have bought it at another store at full price, which will make the franchise as a whole lose revenue. This is obviously not good for the franchise as a whole, but it can be good for the local store manager, if he is having trouble reaching his goals (Baucus, Baucus \& Human 1996). Solving this issue between the HQ and the managers might be very difficult, if not impossible, but this is not within the scope of this paper. The point is that there will always be deviations between what benefits the franchise as a whole, and what benefits the individual store manager.

One of the objectives of this paper is to research whether the different stores within a chain compete internally. Having these sales is a way that the stores could compete with each other. This is of course only true if there are any other franchise stores nearby. In smaller cities where the only other stores nearby belong to the competitors of the franchise, the sales are of course a tool that can be used to compete with these competitors. Though it is unknown how often a store is allowed to have a sale, having discounts on old products going out of stock is allowed, in order to clear up inventory for new products (Christiansen 2015a).

The store manager emphasized the fact that the different stores' customer base is not the same. If a store chooses to have a sale, it does not automatically mean that the store will "steal” customers from the other stores. But when asked about if they are willing to let a customer transfer their lense subscription from on store to another, the employee at Store 1 stated that:

\section{“But we don't turn the customer down, if they wish to transfer from another store to our” (Christiansen 2015a).}

If the distance between the stores is too big the customers might not be willing to travel the extra distance in order to get the discount. The customer of the other franchise stores also have to know that there is a sale at a certain store in order to take advantage of it. This might not be the case with local campaigns (Christiansen 2015a, Christiansen 2015d).

As previously stated, while the prices are set top-down there are certain other parameters that the store managers can control. One of the store managers interviewed put a lot of emphasis on customer service. He was more interested in providing good service and help customers with their needs, than he was in selling as much as possible (Christiansen 2015b). Glasses can last for many years but have to be replaced at some point, either due to changes in strength of the glasses or because of outdated design. With the focus on customer service the possibility of customer retention is increased, and it is more likely that the customer will return when their glasses need replacement. Additionally the manager was determined to have employees at different ages, since glasses are used by people of all ages (Christiansen 2015b). Having employees of all ages is perceived as a good idea, since each employee would have a better understanding of the needs of customers in their age group, rather than someone much older/younger than themselves.

As previously stated there was some inconsistency between the pronouncements in the interviews and the observations conducted in regard to internal competition. The stores looked similar in order to have a recognizable 
concept, which is done through showrooms, core-products, basic prices and perhaps a minimum service level. These are the formal rules set by the HQ. What is left is the informal rules which can be set by the different stores. An example of this is a newly opened store which had a more formal dress code, and the employees were more formal in their interacting with customers. This gave the impression that this store was targeted towards the high-end segment and tourists. The other stores had a more informal atmosphere and were more oriented towards the average person (Christiansen 2015d). The informal rules of a store constitute the cultural and social aspects of the store. While HQ can dictate the formal rules, it would not be possible for them to force a store to have a specific culture or to have a certain social atmosphere. They could of course make certain guidelines about trying to sell more to customers and measure upon it in order to drive behavior in a certain direction. But it is difficult to control these informal rules and therefore not surprising that it is within these the deviations between the different stores are found. It could of course be argued that if it was easy for the franchise to design a set of rules to make the informal rules be part of the formal rules, it might be easier to control the concept of the franchise. Though it is not easy to create a certain culture which fits all the franchise stores since these informal rules needs to fit the local context. There is a big difference in what kind of culture customers expect from a store in a small town or in a large city. The cultural and social aspect is important to make the store fit into the local context, so even if the HQ could dictate it, it would probably still be a good idea to let the local store manager control the informal rules.

\subsection{Section four-Performance measurement and empowerment of employees}

In the following, there will be an analysis of the two interviewed stores and how they are managed differently, mainly how the two managers measure performance of the employees and in general how the culture in the different stores are, and what implications this has for the business model. There are no formal rules given from the HQ on how to do performance management in the different stores. It is up to the local manager of the store to decide if measurement of the employee performance is necessary (Christiansen 2015b). This indicates that how the different managers choose to manage the stores and their internal culture is part of the informal rules.

In City 1, the manager stated that he didn't measure the employee's performance at all, he was of the opinion that it didn't enhance the cohesion in the team and that it just created competition among the employees to sell the most. For him the most important was that the employees worked together as one unit and that the work culture in the store was good. He stated that if choosing to measure on sale, there would be a risk of the employees becoming reluctant to work on tasks that do not result in a direct sale (Christiansen 2015b). This is underpinned by Stanton (2000) who mentions that monitoring employee performance can enhance the employee's effort only on thosetasks being monitored (Stanton 2000). The effect of such performance measure is that the employees will shifts focus from the tasks not monitored to tasks that are monitored (Brewer 1995). The manager in the store in City 1 was aware of the fact that different measurements can have different side effects and that it's not necessary only a good thing to measure the performance of the employees.

This is contrary to how the store in City 2 is managed. There the manager measures the amount of sale each employee creates. The peculiar about this was, when asked to elaborate on how he used this to motivate the employees, he stated that it wasn't intended as a motivating factor and that there were no rewards linked to the measure (Christiansen 2015c). However, according to agency theory the aspect that the employees are aware that they are being monitored can have a motivating effect, even though there are no visible rewards connected to the measurement (Eisenhardt 1989, Larson, Callahan 1990). The manager of the store in City 2 explained that he used it to generate an overview of the individual employees, which could indicate that he uses it as an evaluation tool so that in case of cuts down he can lay off those employees that don't perform in the top regarding to amount of sale. According to the interview, it was not clear that this is the motive behind the measurement, there were no confirmation on whether the employees were aware of this aspect (Christiansen 2015c).

From the analyze above it is clear that the two managers respectively have different leadership styles and that they emphasis different aspect in managing the store and the employees. The manager in City 1 has a softer approach compared to the manager in City 2. Through observation, it is the impression that the manager in City 1 has a more familiar relationship and leadership style, where the manager in City 2 has a more top down approach to managing the store (Christiansen 2015c, Christiansen 2015b, Christiansen 2015d).

This can be due to the fact that the store in City 2 is larger in the number of square feet and in number of employees. Therefore, it can be argued that there is a need for tighter control and more regulation in relation to the employees (Merchant, Var der Stede, Wim A. 2007). It seems as if the culture in City 1 is more informal and relaxed, for example there was placed a couch in the showroom for customers to use when waiting. In relation to the culture, it seems that the store in City 2 has a clear defined hierarchy between the manager and employees, where the hierarchy between the manager and the employees wasn't as eminent in City 1 (Christiansen 2015d, Christiansen 2015c, 
Christiansen 2015b). The above analysis point to that the two managers have different practices relating to how they manage the stores and how they interact with the employees.

The manager in City 1 emphasized aspects such as empowerment of the employees as an intrinsic motivation tool and he had a decentralized decision structure in the store. Each employee has a great deal of responsibility, for example they are the one deciding what kind of spectacle frames the store should have in its assortment. Furthermore, the employees in City 1 have influence on the work schedule, which they plan themselves with supervision from the manager (Christiansen 2015b, Christiansen 2015d). This indicates that the employees take part in the planning and strategy process of the store and that this is affected by the discourse between the employees and the manager.

In relation to the store in City 2 the manager has a centralized decision structure, he is the one taking all the major decisions and the employees don't have much to say in regards to what kind of spectacle frames the store should have in their assortment. The manager mentioned that he got advice from the sales personnel on which model that were selling the best, but that it was his decision in the end. Contrary to the manager in City 1, the manager in this store didn't seem to use intrinsic motivation in such a degree that it would motivate the employees (Christiansen 2015d, Christiansen 2015c, Christiansen 2015b). There is a clear indication that the two stores have different practices, which could mean that they have different business models according to the SAP theory (Jarzabkowski, Paul Spee 2009).

\subsection{Summary}

The above analysis found some indications that the different stores have their own interpretation on the business model of the franchise. While some parameters were dictated by the franchisor, there were other parameters that the store managers could adjust to the local context of their store. The two store managers had different approaches to how they managed their stores. They used performance measurement differently, had variations in how much responsibility the employees had and had different dress codes. Their product assortment was also different as well. These parameters were important for the store in order to satisfy the needs of the local customers, as consumer tastes in the local market varied from store to store.

\section{Discussion and reflection}

\subsection{Why would the stores compete internally?}

As stated earlier, there is a risk of conflicting goals or interests between franchisors and franchisees, but why is this an issue for the entire company? According to Davies et al. 2011 interests are often dissimilar e.g. due to their individual survival criteria. HQ normally seeks to maximize profit for all units of franchisees whereas the stores only focus on their own profit due to their entrepreneurial thinking:

"... franchise networks can be characterized as a community of entrepreneurs, each of which has aspirations toward autonomy and innovativeness" (Davies et al. 2011).

To suppress this issue companies must enforce standards and restraints to control the units but having the interests of the stores in mind as well (Davies et al. 2011, Baucus, Baucus \& Human 1996). We have seen that this is also the case in our case company where there are budgets that must be reached, rules to be followed to maintain a certain standard etc. If the stores feel unfairly treated or cannot reach their goals, there is a risk of disloyal behavior such as internal competition in order to survive (Christiansen 2015b, Baucus, Baucus \& Human 1996, Martín-Herrán, Sigué \& Zaccour 2011).

Based on our analysis there does not seem to be much indication that the different stores compete internally, at least not intentionally. The stores' local campaigns could mean that some customers buy their products in another franchisee store than the one they normally use and this is difficult to avoid due to possible spillover or predatorily outcome. So it can be argued that the franchise as a whole can actually benefit from the local campaigns but that it might both hurt and aid the franchisees in between. This could be the case here since the case company told us that they don't compete internally, although they don't deny an approaching customer from a fellow franchisee. Additionally it is an important tool for the individual stores in their competition with rival stores (Martín-Herrán, Sigué \& Zaccour 2011, Christiansen 2015a, Christiansen 2015b, Christiansen 2015c).

While there was not much indication of that there is internal competition, the two managers have their own interpretation of the business model. This is supported by that the practice in the two stores are not the same, which 
seems mainly to be explained by the managers' different leadership styles. The discourse is different in the two stores as well, which in turn have implications for the internal culture and how the employees perceive their workplace.

Both managers have their own cultural backgrounds and experience on how to do things. This affects how the stores are managed, in City 1 the manager emphasis empowerment of the employees and has a decentralized decision structure, where manager in City 2 has a more centralized decision structure (Christiansen 2015d).

The most eminent point of difference is how the two managers use performance measurement of the employees or lack thereof. The manager in City 2 measures the amount of sale, but he has not linked any reward in relation to the measurement (Christiansen 2015c). It can be discussed if there are any motivational effects of these measures. In the article by Cinquini et al. (2003) it is mentioned that there must be some value attached in order to motivate the individual otherwise there will be no action (Cinquini et al. 2013). This is contrary to Stanton (2000), which state that even the fact that the employees are monitored can have a motivating effect by attracting attention to task effort (Stanton 2000, Brewer 1995).

\subsection{Further research}

This study indicated that the different stores operate with different business models. Through this case study the focus was only on a single case company, which revealed that the phenomena of Coexisting Business Models exists. If these findings should be generalized, this phenomenon would need to be supported further by applying the hypothesis in more case studies conducted on several and various case companies. This is necessary in order to test the robustness of the findings in this paper, and in order to theoretically generalize the findings to other contexts (Ryan, Scapens \& Theobald 2002).

After completing this paper the hope is that the finding will open up for further research on Business Models and Coexisting Business Models. Hopefully this will help the concept establish theoretical grounding, because this case study is only the first step towards this goal within the field of Management Accounting research. Further research within this field is expected to increase the knowledge and lead to findings that are able to support the findings in this case study and perhaps expand this research even further.

\subsection{Conclusion}

This study has revealed different definitions of the concept Business Models and have created its own in order to shed light on how dissimilar business models co-exist in a franchise. The research is based on an empirical case study in a franchise chain and through the Practice Theory- and SAP framework sought to demonstrate whether there exist different business models within the franchise, which factors it may influence and the conflicts/benefits it can bring along. The analysis concludes that there are diverse business models within the case company due to different practices, interests and ways of doing business. No apparent conflicts were discovered but some theories in contrast with the empirical analysis could indicate future risks of internal competition if interests between franchisor and franchisee become too diverse. This study suggests that dissimilar business models within a franchise can co-exist with the right conditions but there is a risk of dangers such as disloyal behavior due to different goals. 


\section{References}

Anonymous 2015, , www."case company".dk [2015, March].

Baucus, D.A., Baucus, M.S. \& Human, S.E. 1996, "Consensus in Franchise Organizations: A Coorporative Arrangement among Entrepreneurs", Journal of Business Venturing, vol. 11, no. 5, pp. 359-378.

Bock, A.J., Opsahl, T., George, G. \& and Gann, D.M. 2012, "The effects of culture and structure on strategic flexibility during business model innovation", Journal of Management studies, vol. 49, no. 2, pp. 279-305.

Brewer, N. 1995, "The Effects of Monitoring Individual and Group Performance on the Distribution of Effort Across Tasks1", Journal of Applied Social Psychology, vol. 25, no. 9, pp. 760-777.

Brickley, J.A., Dark, F.H. \& Weisbach, M.S. 1991, "An Agency Perspective on Franchising", FM: The Journal of the Financial Management Association, vol. 20, no. 1, pp. 27-35.

Casadesus-Masanell, R. \& Ricart, J.E. 2010, "From Strategy to Business Models and onto Tactics", Long Range Planning, vol. 43, no. 2/3, pp. 195-215.

Cavalcante, S., Kesting, P. \& Ulhøi, J. 2011, "Business model dynamics and innovation : (re)establishing the missing linkages", Management Decision, vol. 49, no. 8, pp. 1327-1342.

Chalykoff, J. \& Kochan, T.A. 1989, "Computer-aided Monitoring: Its Influence on Employee Job Satisfaction and Turnover", Personnel Psychology, vol. 42, no. 4, pp. 807-834.

Christiansen, J.D.F. 2015a, Interview with employee of store on 23/03.

Christiansen, J.D.F. 2015b, Interview with first manager of store on 23/03.

Christiansen, J.D.F. 2015c, Interview with second manager of store on 08/04.

Christiansen, J.D.F. 2015d, Observation at physical stores.

Cinquini, L., Mitchell, F., Nørreklit, H. \& Tenucci, A. 2013, "Methodologies for managing performance measurement", The Routledge Companion to Cost Management, Routledge, London, , pp. 360-380.

Dalby, J., Lueg, R., Nielsen, L. S., Pedersen, L., \& Tomoni, A. C. 2014. National culture and business model change: a framework for successful expansions. Journal of Enterprising Culture, 22(4): 463-483.

Das, S.C. 2010, Management control systems: Principles and practices, 1 Edition edn, PHI Learning.

Davies, M.A.P., Lassar, W., Manolis, C., Prince, M. \& Winsor, R.D. 2011, "A model of trust and compliance in franchise relationships", Journal of business venturing, vol. 26, no. 3, pp. 321- 340.

Eisenhardt, K.M. 1989, "Agency Theory: An Assessment and Review", Academy of Management Review, vol. 14, no. 1 , pp. 57-74.

Feldman, M.S. \& Orlikowski, W.J. 2011, "Theorizing Practice and Practice Theory", Organization Science, vol. 22, no. 5, pp. 1240-1253.

Friis, J. D., Lueg, R., Mayanja, R., Salling, S. T., \& Sørensen, K. A. M. 2015. Business model or strategy: which comes first? A lifecycle perspective in the Scandinavian software industry. Problems and Perspectives in Management, 13(2): 161-169.

Haubro, A. P., Lomholt, H. A., Lueg, R., Nielsen, S. V., \& Knudsen., U. 2015. Tactical and strategic choices in business models: evidence from a Danish fashion outlet. Journal of Fashion Marketing and Management: forthcoming.

Jarzabkowski, P. \& Paul Spee, A. 2009, "Strategy-as-practice: A review and future directions for the field", International Journal of Management Reviews, vol. 11, no. 1, pp. 69-95.

Johnson, M.W., Christensen, C.M. \& Kagermann, H. 2008, "Reinventing your Business Model", Harvard Business Review, vol. 86, no. 12, pp. 51-59.

Kotter, P. J. 1995, “Leading Change: Why Transformation Efforts Fail”, Harvard Business Review, vol. 73, no. 2, pp. 59-67.

Larsen, M. K., Lueg, R., Nissen, J. L., Schmaltz, C., \& Thorhauge, J. R. 2014. Can the business model of Handelsbanken be an archetype for small and medium sized banks? A comparative case study. Journal of Applied Business Research, 30(3): 869-882.

Larson, J.,James R. \& Callahan, C. 1990, "Performance Monitoring: How It Affects Work Productivity", Journal of Applied Psychology, vol. 75, no. 5, pp. 530-538.

Lueg, K., Lueg, R., Andersen, K., \& Dancianu, V. 2016. Integrated reporting with CSR practices: a pragmatic constructivist case study in a Danish cultural setting. Corporate Communications: An International Journal, 21(1): 20-35.

Lueg, R., Clemmensen, S. N., \& Pedersen, M. M. 2015. The role of corporate sustainability in a low-cost business model - A case study in the Scandinavian fashion industry Business Strategy and the Environment, 24(5): 344359.

Lueg, R., Malinauskaite, L., \& Marinova, I. 2014. The vital role of business processes for a business model: the case of a startup company. Problems and Perspectives in Management, 12(4): 213-220. 
Lueg, R., Nedergaard, L., \& Svendgaard, S. 2013. The use of intellectual capital as a competitive tool: a Danish case study. International Journal of Management, 30(2): 217-231.

Malmmose, M., Lueg, R., Khusainova, S., Iversen, P. S., \& Panti, S. B. 2014. Charging customers or making profit? Business model change in the software industry. Journal of Business Models, 2(1): 19-32.

Martín-Herrán, G., Sigué, S.P. \& Zaccour, G. 2011, "Strategic interactions in traditional franchise systems : are franchisors always better off?", European Journal of Operational Research, vol. 213, no. 3, pp. 526-537.

Merchant, K.A. \& Var der Stede, Wim A. 2007, Management Control Systems: Performance Measurement, Evaluations and Incentives, 2nd edn, Financial Times/Prentice Hall, Harlow.

Osterwalder, A., Pigneur, Y. \& Tucci, C.L. 2005, "Clarifying Business Models: Origins, Present, and Future of the Concept", Communications of the Association for Information Systems, vol. 16, pp. 1-25.

Otley, D.T. \& Berry, A.J. 1994, "Case Study Research in Management Accounting and Control", Management Accounting Research, vol. 5, no. 1, pp. 45-65.

Ryan, B., Scapens, R.W. \& Theobald, M. 2002, Research Method \& Methodology in Finance \& Accounting, 2nd edn, South-Western Cengage Learning.

Seddon, P.B., Lewis, G.P., Freeman, P. \& and Shanks, G. 2004, "The Case for viewing business models as abstractions of strategy", Communications of the Association for Information Systems, vol. 13, pp. 427-442.

Stanton, J.M. 2000, "Reactions to Employee Performance Monitoring: Framework, Review, and Research Directions", Human Performance, vol. 13, no. 1, pp. 85-113.

Teece, D.J. 2010, "Business models, Business strategy and innovation", Longe Range Planning, vol. 43, no. 2-3, pp. 172-194.

Vaara, E. \& Whittington, R. 2012, "Strategy-as-Practice:Taking Social Practices Seriously", The Academy of Management Annals, vol. 6, no. 1, pp. 285-336.

Whittle, A. \& Mueller, F. 2010, "Strategy, enrolment and accounting: the politics of strategic ideas", Accounting, Auditing \& Accountability Journal, vol. 23, no. 5, pp. 626-646.

Yin, R.K. 2014, Case Study Research: Design and Methods, 5th edn, SAGE Publications, Inc. 